\title{
Cross sectional echocardiographic anatomy of common atrioventricular valve in atrial isomerism
}

\author{
JUN ARISAWA, * SHIZUO MORIMOTO, * JUNPEI IKEZOE, * SEIKI HAMADA, * \\ TAKAHIRO KOZUKA, * TETSUYA SANO, $\dagger$ MINORU OGAWA, $\dagger$ \\ HIKARU MATSUDA, $\ddagger$ YASUNARU KAWASHIMA \\ From the Departments of $\star R$ Radiology and $\nmid$ Paediatrics and $\ddagger$ First Surgical Department, Osaka University \\ Medical School, Osaka, Japan
}

SUMMARY The morphology of the common atrioventricular valve and its relation to the ventricles was assessed by cross sectional echocardiography in 17 patients with atrial isomerism-four with left isomerism and 13 with right isomerism. In 13 patients the atrioventricular valve consisted of four leaflets: a large anterosuperior leaflet, two lateral leaflets, and a posteroinferior leaflet. The remaining four patients had two anterosuperior leaflets. Five patients had hearts with a double inlet right ventricle and all of them had a rudimentary left ventricle. All the commissures were attached to the right ventricle. Five patients showed severe right ventricular dominance. The atrioventricular morphology in these five hearts differed from that in the patients with the usual atrial arrangement, concordant atrioventricular connection, and hypoplasia of the left ventricle. Only the anterosuperior leaflet bridged the rudimentary left ventricle, and the posteroinferior leaflet was tethered to the ventricular septal crest. Six patients had a biventricular atrioventricular connection and two of them showed mild right ventricular dominance. The atrioventricular morphology in these hearts was the same as that seen in the patients with usual atrial arrangement and a concordant atrioventricular connection. The remaining patient showed dominance of the left ventricle. Only the anterosuperior leaflet bridged the rudimentary right ventricle in this heart.

Atrial isomerism is commonly associated with anomalies of venous drainage, atrioventricular connection, ventricular morphology, ventriculoarterial connection, and a pulmonary obstructive lesion..$^{1-3}$ In atrial isomerism a common atrioventricular valve is the most frequent mode of atrioventricular connection and the ventricular morphology is variable. ${ }^{4}$ All types of heart with a double inlet ventricle are common in atrial isomerism. ${ }^{4} \mathrm{~A}$ common atrioventricular valve was easily detected by cross sectional echocardiography in hearts with a double inlet ventricle. $^{5}$ The detailed echocardiographic detection of the position of attachment of the commissural chordae of the anterosuperior leaflets of the common atrioventricular valve in the hearts with the usual atrial arrangement and concordant atrioventricular connection has been reported. ${ }^{6}$ But there is no clinical

Requests for reprints to Dr Jun Arisawa, Department of Radiology, Osaka University Medical School, 1-1-50 Fukushima, Fukushimaku, Osaka 553, Japan.

Accepted for publication 20 April 1989 or pathological study to determine what part of the common atrioventricular valve is inserted into a rudimentary ventricle in a heart with a dominant ventricle or whether the shape of the common atrioventricular valve in the heart with atrial isomerism and a biventricular atrioventricular connection is the same as that in hearts with the usual atrial arrangement and concordant atrioventricular connection.

We used cross sectional echocardiography to study the common atrioventricular valve and its relation to the shape and size of the ventricle in hearts showing atrial isomerism.

\section{Patients and methods}

Seventeen patients with a common atrioventricular valve associated with thoracic isomerism were examined during a two year period from 1 March 1983 at Osaka University Medical School. Thoracic isomerism was identified by a plain chest radiograph and angiocardiography. Right isomerism was diag- 
nosed if the chest radiograph showed bilateral short main bronchi and angiography showed bilateral eparterial bronchi. Left isomerism was diagnosed if there were bilateral long main bronchi and hyparterial bronchi. Atrial isomerism was confirmed by intraoperative examination of the atrial appendages in eight patients and at necropsy in two patients. The cardiac axis and ventricular morphology were identified by angiography. The relation of the ventricles to the common atrioventricular valve was established by both cross sectional echocardiography and ventriculography.

The patients were examined with a HewlettPackard sector scanner $77020 \mathrm{~A}$ and a 3.5 or $5.0 \mathrm{MHz}$ transducer in the apical and precordial four chamber views, precordial short axis view, and subcostal short axis view. We examined the number of leaflets, number of papillary muscles in the left ventricle, and the position of attachment of each commissural chorda in relation to ventricular morphology and the position of the trabecular ventricular septum.

\section{Results}

We identified left isomerism in four patients and right isomerism in 13 cases (table). The table also shows the position of the cardiac apex, the atrioventricular connection, the ventricular size, and the ventriculoarterial connection. Two ventricles were identified in all the patients. A morphologically right ventricle was situated anteriorly in 15 patients and posteriorly in two (cases 12 and 17) with right isomerism.
NUMBER OF LEAFLETS

In 13 of the 17 common atrioventricular valves four leaflets (anterosuperior, posteroinferior, and two lateral leaflets) were identified echocardiographically. Two anterosuperior leaflets were shown in another four patients (fig 1).

\section{SHAPE OF LEAFLETS IN 10 PATIENTS WITH CONSIDERABLE RIGHT VENTRICULAR \\ DOMINANCE}

In five patients all the commissures were attached to the right ventricle (fig $1 \mathrm{a}$ and fig 2 ). In another five patients the anterosuperior leaflet bridged the rudimentary left ventricle, and the commissure between the left lateral leaflet (which was situated at the left ventricular side) and a posteroinferior leaflet was attached to the ventricular septal crest (figs $1 b$ and $1 c$, fig 3).

\section{ARRANGEMENT OF LEAFLETS IN SIX PATIENTS WITH MILD RIGHT VENTRICULAR DOMINANCE OR WITH BIVENTRICULAR ATRIOVENTRICULAR CONNECTION}

In one of the two patients with mild right ventricular dominance we found two anterosuperior leaflets, and the commissure between these leaflets was attached to a papillary muscle on the right ventricular aspect of the anterior ventricular septum (fig 1d). The posteroinferior leaflet also bridged part of the left ventricle in this patient. In another patient the anterosuperior leaflet was free floating and both the anterior and posteroinferior leaflets straddled the interventricular septum (fig le).

Table Position of cardiac apex, atrioventricular connection, ventricular size, and ventriculoarterial connection in 17 patients with atrial isomerism and common atrioventricular valve. The right ventricular chamber was posteriorly positioned in patients 12 and 17 and anteriorly in 15 patients

\begin{tabular}{|c|c|c|c|c|c|c|}
\hline $\begin{array}{l}\text { Patient } \\
\text { No }\end{array}$ & Age & Sex & $\begin{array}{l}\text { Type of } \\
\text { isomerism }\end{array}$ & $\begin{array}{l}\text { Position } \\
\text { of } \\
\text { cardiac apex }\end{array}$ & $\begin{array}{l}\text { Atrioventricular connection and } \\
\text { ventricular size }\end{array}$ & $\begin{array}{l}\text { Ventriculoarterial } \\
\text { connection }\end{array}$ \\
\hline $\begin{array}{r}1 \\
2 \\
3 \\
4 \\
5 \\
6 \\
7 \\
8 \\
9 \\
10 \\
11 \\
12 \\
13 \\
14 \\
15 \\
16 \\
17\end{array}$ & $\begin{array}{l}6 \mathrm{mnth} \\
5 \mathrm{yr} \\
11 \mathrm{yr} \\
2 \mathrm{yr} \\
6 \mathrm{yr} \\
1 \mathrm{yr} \\
8 \mathrm{yr} \\
2 \mathrm{yr} \\
7 \mathrm{yr} \\
8 \mathrm{yr} \\
5 \mathrm{yr} \\
4 \mathrm{yr} \\
4 \mathrm{mnth} \\
1 \mathrm{yr} \\
3 \mathrm{mnth} \\
15 \mathrm{yr} \\
11 \mathrm{yr}\end{array}$ & $\begin{array}{l}\mathbf{F} \\
\mathbf{M} \\
\mathbf{M} \\
\mathbf{M} \\
\mathbf{M} \\
\mathbf{F} \\
\mathbf{M} \\
\mathbf{F} \\
\mathbf{M} \\
\mathbf{F} \\
\mathbf{M} \\
\mathbf{F} \\
\mathbf{M} \\
\mathbf{M} \\
\mathbf{M} \\
\mathbf{F} \\
\mathbf{F}\end{array}$ & $\begin{array}{l}\text { Left } \\
\text { Left } \\
\text { Left } \\
\text { Left } \\
\text { Right } \\
\text { Right } \\
\text { Right } \\
\text { Right } \\
\text { Right } \\
\text { Right } \\
\text { Right } \\
\text { Right } \\
\text { Right } \\
\text { Right } \\
\text { Right } \\
\text { Right } \\
\text { Right }\end{array}$ & $\begin{array}{l}\text { Left } \\
\text { Left } \\
\text { Right } \\
\text { Right } \\
\text { Left } \\
\text { Left } \\
\text { Left } \\
\text { Left } \\
\text { Left } \\
\text { Left } \\
\text { Left } \\
\text { Left } \\
\text { Right } \\
\text { Right } \\
\text { Right } \\
\text { Right } \\
\text { Right }\end{array}$ & $\begin{array}{l}\text { Double inlet right ventricle } \\
\text { Biventricular A-V connection } \\
\text { Right ventricular dominance } \\
\text { Biventricular A-V connection } \\
\text { Double inlet right ventricle } \\
\text { Double inlet right ventricle } \\
\text { Double inlet right ventricle } \\
\text { Right ventricular dominance } \\
\text { Right ventricular dominance } \\
\text { Right ventricular dominance } \\
\text { Biventricular A-V connection } \\
\text { Biventricular A-V connection } \\
\text { Double inlet right ventricle } \\
\text { Right ventricular dominance } \\
\text { Right ventricular dominance } \\
\text { Left ventricular dominance } \\
\text { Right ventricular dominance }\end{array}$ & $\begin{array}{l}\text { DORV, PS } \\
\text { Ao from RV, PA } \\
\text { DORV, PS } \\
\text { Ao from RV, PA } \\
\text { Ao from RV, PA } \\
\text { Ao from RV, PA } \\
\text { DORV, PS } \\
\text { DORV, PS } \\
\text { DORV, PS } \\
\text { DORV, PS } \\
\text { DORV, PS } \\
\text { Ao from RV, PA } \\
\text { Ao from RV, PA } \\
\text { Ao from RV, PA } \\
\text { DORV, PS } \\
\text { TGA(1), PS } \\
\text { DORV, PS }\end{array}$ \\
\hline
\end{tabular}

Ao, aorta; DORV, double outlet right ventricle; PA, pulmonary atresia; PS, pulmonary stenosis; RV, right ventricle; TGA(1), transposition of great arteries with left sided aorta. 


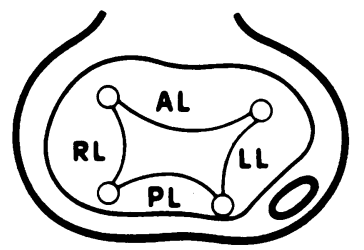

(a) 5

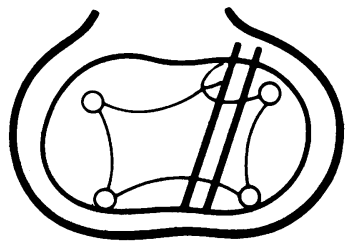

(d) 1

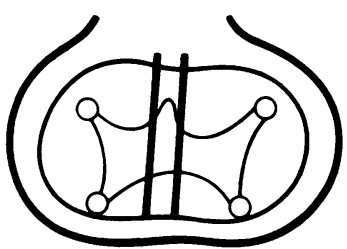

(9) 1

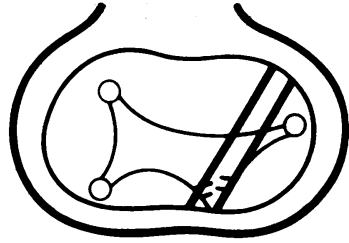

(b) 4

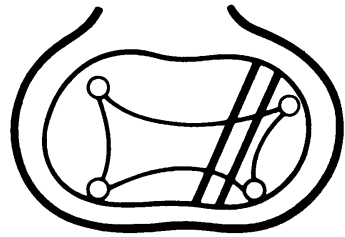

(e) 1

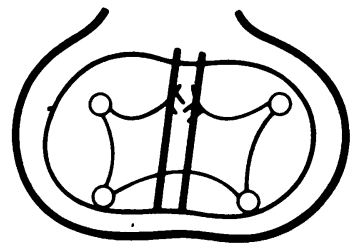

(b) 1

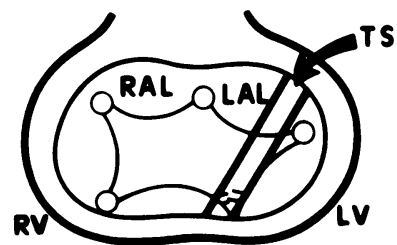

(c) 1

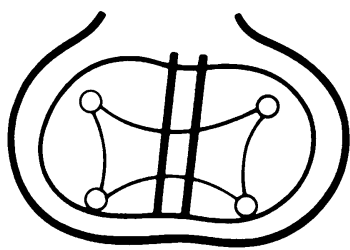

(†) 2

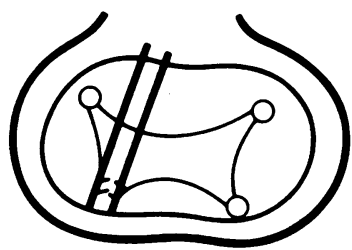

(i) 1

Fig 1 Variation of the position of commissures detected by echocardiography. The leaflets of the common atrioventricular valve and the position of the commissures are shown in relation to the papillary muscles and trabecular ventricular septum in a short axis view. The right ventricle is on the left side. The number of patients is shown in parentheses. $R V$, right ventricle; $L V$, left ventricle; $A L$, anterosuperior leaflet; $P L$, posteroinferior leaflet; $R L$, right lateral leaflet; $L L$, left lateral leaflet; $T S$, trabecular septum; $R A L$, right anterosuperior leaflet; $L A L$, left anterosuperior leaflet.

In two of four patients with a biventricular atrioventricular connection the anterosuperior leaflet was free floating and both the anterosuperior and posteroinferior leaflets straddled the interventricular septum (fig 1f). In another two patients two anterior leaflets were shown. One of them had no commissural cord between two anterosuperior leaflets (fig 1g, fig 4) and in the other the commissure between these leaflets was attached to the crest of interventricular septum (fig $1 \mathrm{~h}$, fig 5 ).

MORPHOLOGY OF LEAFLETS IN A PATIENT WITH LEFT VENTRICULAR DOMINANCE

The anterosuperior leaflet straddled the ventricular septum, and the commissure between right lateral and posteroinferior leaflets was attached to the ventricular septal crest (fig 1i, fig 6 ).

\section{Discussion}

A definite diagnosis of atrial isomerism can be made on the basis of the atrial morphology, especially the shape of the atrial appendage. ${ }^{7}$ The morphology of the atrial appendage can be shown by atriography ${ }^{8}$ or at operation. But atriography cannot be performed in all patients. There are only a few exceptions that show discordance between the thoracic situs and the atrial situs. ${ }^{9}$ The most reliable non-invasive method of diagnosis is, therefore, to show the bronchial situs by a plain chest radiograph. ${ }^{10-12}$ We detected bronchial isomerism by showing symmetrical main bronchi in a chest radiograph in our series. The course of the pulmonary arteries, which was shown by cineangiocardiography, was used to establish right or left sidedness. 

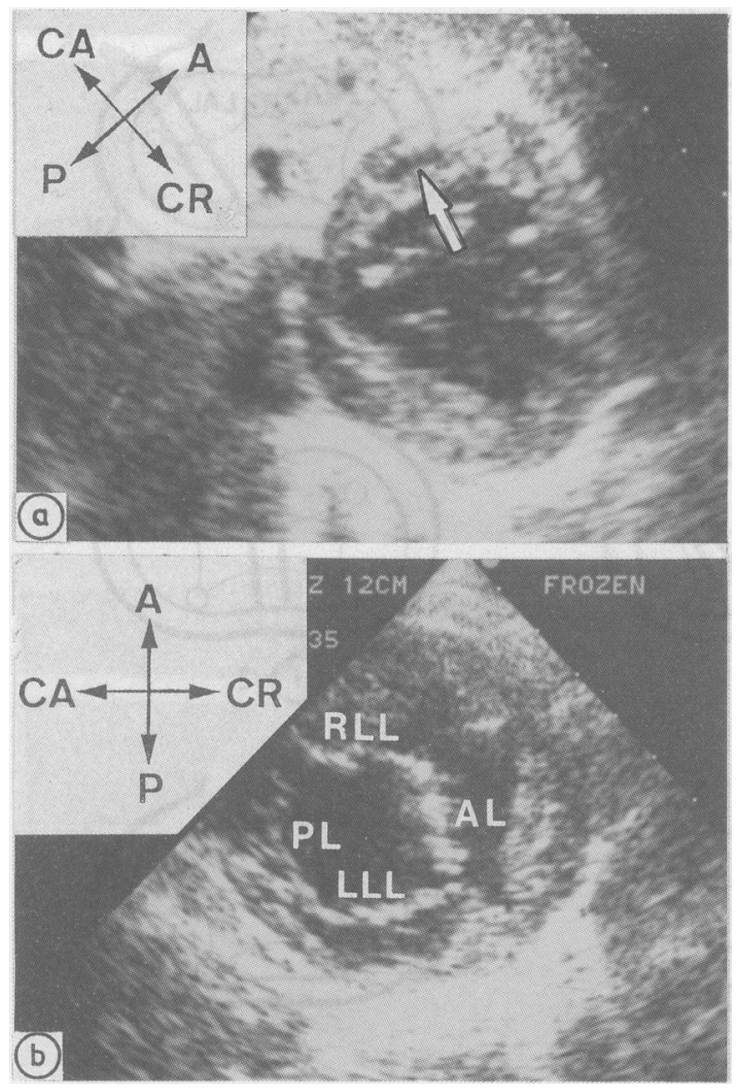

Fig 2 Echocardiograms from a six year old boy with right isomerism (case 5) and left sided heart. (a) Subcostal short axis view showing a small rudimentary ventricle (arrow) positioned posteriorly with no chordal insertion into this ventricle. (b) Precordial short axis view showing four leaflets, all attached to the right ventricle.

$A L$, anterosuperior leaflet; $P L$, posteroinferior leaflet;

$R L L$, right lateral leaflet; $L L L$, left lateral leaflet;

$C R$, cranial; $C A$, caudal; $A$, anterior; $P$, posterior.

Cross sectional echocardiographic identification of common atrioventricular valve in hearts with a double inlet ventricle is regarded as reliable. ${ }^{513} \mathrm{We}$ detected the cases of common atrioventricular valve by cross sectional echocardiography. Those with atresia of the left atrioventricular valve were also identified by cross sectional echocardiography and excluded from this study. Ventriculography was performed in all the patients and each of them had only one atrioventricular valve.

The common atrioventricular valve in hearts with the usual atrial arrangement and concordant atrioventricular connection was reported to have five leaflets-two anterosuperior, one posteroinferior, and right lateral and left lateral leaflets. ${ }^{14}$ They were classified according to the position of attachment of commissural chordae of two anterosuperior leaflets. ${ }^{14}{ }^{15}$ Cross sectional echocardiography was reported to be the most effective method of detecting the detailed morphology of the common atrioventricular valve in terms of the description of the tethering position of the chordae of anterosuperior leaflets. ${ }^{6}$ In our series, we identified four leaflets in nine of 10 hearts with a double inlet right ventricle or showing considerable right ventricular dominance. A necropsy study of hearts with double inlet right ventricle showed that the valve generally has four leaflets. ${ }^{17}$ Four leaflets were also shown in three of six hearts with biventricular atrioventricular connec-
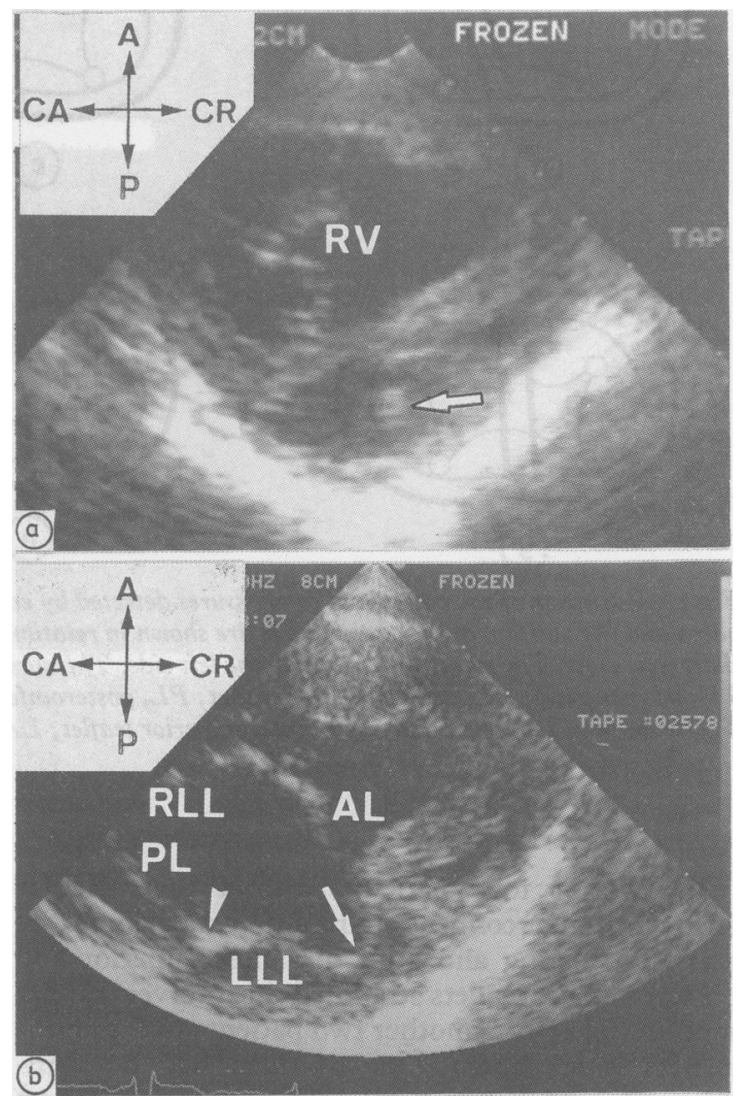

Fig 3 Echocardiograms from a 11 year old boy (case 3) with left isomerism and a right sided heart. (a) Short axis view at papillary muscle level showing a dominant right ventricle (RV) and a papillary muscle (arrow) in the rudimentary left ventricle. (b) Short axis view at atrioventricular valve level showing the commissure (arrow) between the anterosuperior leaflet $(A L)$ and left lateral leaflet $(L L L)$ attached to the papillary muscle in the rudimentary left ventricle and the commissure (arrow head) between left lateral leaflet ( $L L L)$ and posteroinferior leaflet $(P L)$ attached to the ventricular septal crest. 


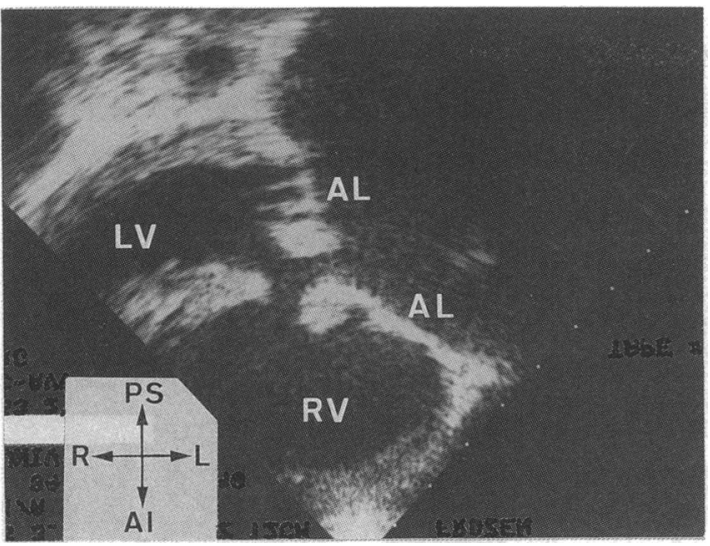

Fig 4 Echocardiogram from a two year old boy (case 4) with left isomerism and a right sided heart. The four chamber view shows two well formed ventricles and a severely dilated atrium. The two anterosuperior leaflets $(A L)$ were of equal size. There was no chordal tethering of the commissure between these two leaflets to the crest of ventricular septum or to a papillary muscle and the commissure was free floating. $R V$, right ventricle; $L V$, left ventricle; $R$, right; $L$, left; $A I$, anteroinferior; $P S$, posterosuperior.

tion. It was impossible to detect another small right anterosuperior leaflet in the patients with a free floating large anterosuperior leaflet in the hearts of our series, as was shown in a necropsy study of common atrioventricular valve in hearts with the usual atrial arrangement and a concordant atrioventricular connection. ${ }^{14}$

In patients with two papillary muscles in the left ventricle and with slight right ventricular dominance or two well formed ventricles, the patterns of tethering of anterosuperior leaflets corresponded with those seen in patients with the usual atrial arrangement and a concordant atrioventricular connection-that is a free floating large anterosuperior leaflet, tethering of the commissure of two anterosuperior leaflets on to the medial papillary muscle, or tethering on to the crest of ventricular septum.

Left ventricular dominance was seen in only one patient, and in this patient the anterosuperior leaflet bridged the right ventricle while the commissural chordae of right lateral and posteroinferior leaflets were tethered on to the crest of the ventricular septum. In a necropsy study of patients with dominant left ventricles, only one commissural attachment to the right ventricle was shown and that was between the anterosuperior bridging leaflet and the anterolateral papillary muscle. ${ }^{17}$

The morphological characteristics of the common atrioventricular valve in atrial isomerism with right ventricular dominance or in hearts with double inlet right ventricle are not well known. In those patients with straddling of the mitral valve and two atrioventricular valves, the left ventricle generally had two papillary muscles, while the anterior papillary muscle was usually absent when there was one papillary muscle in the left ventricle. ${ }^{18}$ On the other hand, in our series, the posterior papillary muscle was absent and the chordae of the commissure between the left lateral and posteroinferior leaflets were tethered to the crest of ventricular septum when one papillary muscle was found in the left ventricle. These differences suggest that the development of left ventricular hypoplasty differs in hearts with a straddling mitral valve and those with atrial isomerism and a common atrioventricular valve.

Hypoplasia and dysplasia of the left ventricular
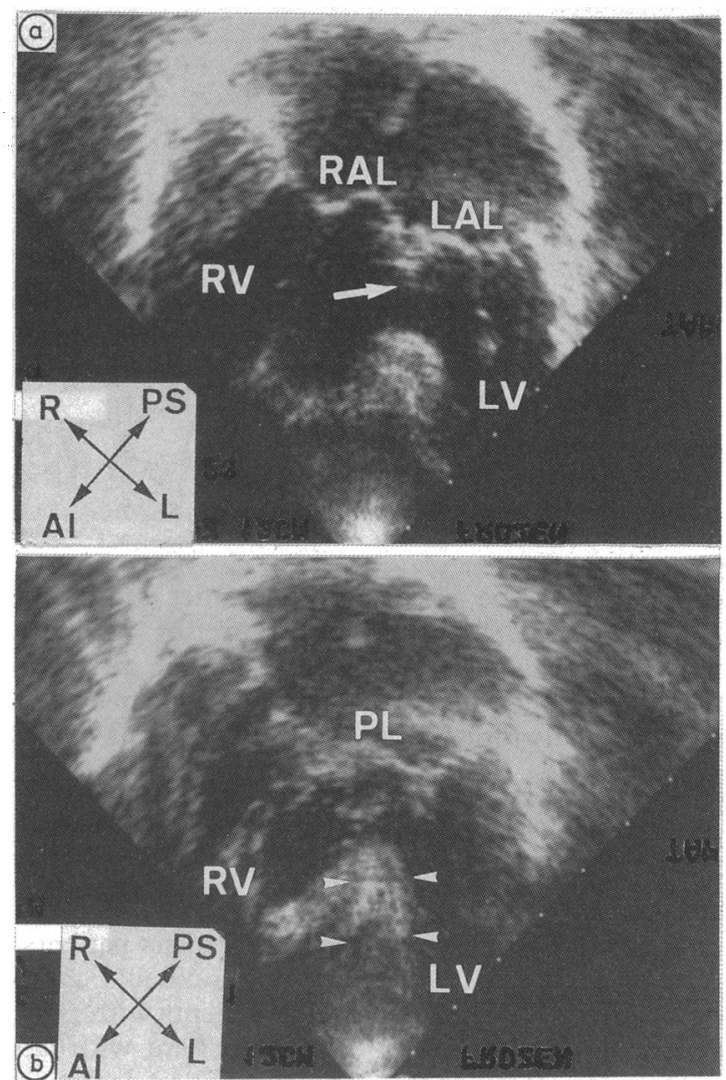

Fig 5 Echocardiograms from a five year old boy (case 11) with right isomerism and a left sided heart. (a) The four chamber view shows two anterosuperior leaflets. Chordae (arrow) from the commissure of these leaflets were attached to the crest of the interventricular septum. RAL, right anterosuperior leaflet; $L A L$, left anterosuperior leaflet. (b) The four chamber view with posterior tilt shows a posteroinferior leaflet (arrow) that bridged the interventricular septum (arrow heads). 


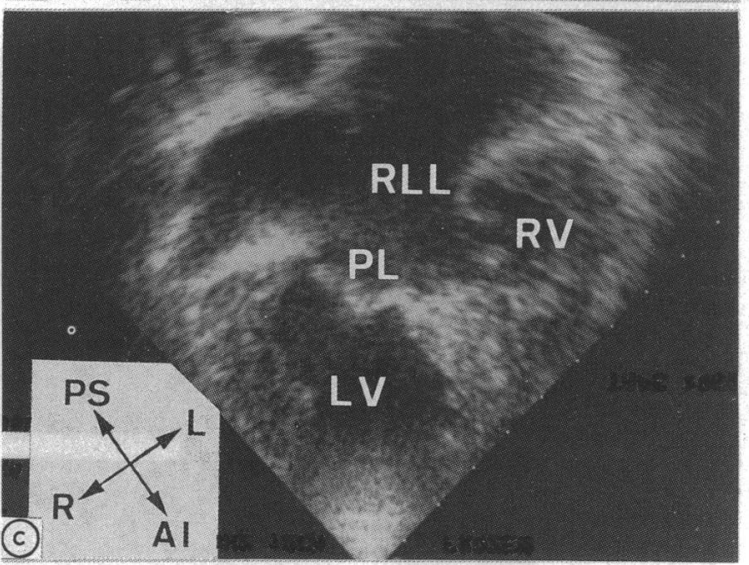

Fig 6 Echocardiograms from a 15 year old girl (case 16) with right isomerism and a right sided heart. (a) The four chamber view shows the dominant left ventricle ( $L V$ ) bridged by the anterosuperior leaflet (arrow). $R V$, right ventricle. (b) A four chamber view of systole with posterior tilt shows the commissure (arrow) between the posteroinferior and right lateral leaflets attached to the crest of the interventricular septum. (c) The same view in diastole shows the posteroinferior leaflet (PL) opening into the left ventricle ( $L V)$ and a right lateral leaflet ( $R L L)$ opening into the right ventricle.

component of the posteroinferior leaflet and hypoplasia of the left ventricular posterior papillary muscle were reported in cases of common atrioventricular valve with the usual atrial arrangement, left ventricular hypoplasia, and normal relations of the great vessels. ${ }^{19}$ The tethering of the commissure between the left lateral and posteroinferior leaflets to the crest of the ventricular septum that we found has not been described before in patients with the usual atrial arrangement.

Corrective surgery was performed in six patients. A total cavopulmonary shunt or modified Fontan procedure was performed in five patients with right ventricular dominance and in the patient with left ventricular dominance. Atrioventricular septation had been planned in one of the patients with right ventricular dominance, in whom the rudimentary left ventricle was large. The echocardiographic examination provided valuable information on which to base the surgical approach in this patient. Cross sectional echocardiography showed an atrioventricular valve of the type shown in fig $1 \mathrm{~b}$, and the modified Fontan procedure was performed.

We examined by echocardiography the range of types of common atrioventricular valve in atrial isomerism. We found that the atrioventricular morphology in those with partial insertion of a common atrioventricular valve into the rudimentary left ventricle in atrial isomerism differed from that in hearts with the usual atrial arrangement, concordant atrioventricular connection, and hypoplasia of the left ventricle.

\section{References}

1 Moller JH, Nakib A, Anderson RC, Edwards JE. Congenital cardiac disease associated with polysplenia. A developmental complex of bilateral "LeftSidedness". Circulation 1967;36:789-99.

2 Liberthson RR, Hastreiter AR, Shinha SN, Bharati S, Novak GM, Lev M. Levocardia with visceral heterotaxy-isolated levocardia: pathologic anatomy and its clinical implications. Am Heart $J$ 1973;85: 40-54.

3 Rose V, Izukawa T, Moës CAF. Syndromes of asplenia and polysplenia. A review of cardiac and non-cardiac 
malformations in 60 cases with special reference to diagnosis and prognosis. Br Heart J 1975;37:840-52.

4 De Tommasi SM, Daliento L, Ho SY, Macartney FJ, Anderson RH. Analysis of atrioventricular junction, ventricular mass, and ventriculoarterial junction in 43 specimens with atrial isomerism. Br Heart J 1981;45: $236-47$.

5 Smallhorn JF, Tommasini G, Macartney FJ. Twodimensional echocardiographic assessment of common atrioventricular valves in univentricular hearts. Br Heart J 1981;46:30-4.

6 Smallhorn JF, Tommasini G, Anderson RH, Macartney FJ. Assessment of atrioventricular septal defects by two dimensional echocardiography. $\mathrm{Br}$ Heart $J$ 1982;47:109-21.

7 Macartney FJ, Zuberbuhler JR, Anderson RH. Morphological considerations pertaining to recognition of atrial isomerism. Consequence for sequential chamber localisation. Br Heart J 1980;44:657-67.

8 Arciniegas JG, Soto B, Coghlan HC, Bargeron LM. Congenital heart malformations: sequential angiographic analysis. AJR 1981;137:673-81.

9 Caruso G, Becker AE. How to determine atrial situs? Considerations initiated by 3 cases of absent spleen with a discordant anatomy between bronchi and atria. Br Heart J 1979;41:559-67.

10 Van Mielop LHS, Eisen S, Schiebler GJ. The radiographic appearance of the trancheobronchial tree as an indicator of visceral situs. Am J Cardiol 1970; 26:432-5.

11 Deanfield JE, Leanage R, Stroobant J, Chrispin AR, Taylor JFN, Macartney FJ. Use of high kilovoltage filtered beam radiographs for detection of bronchial situs in infants and young children. Br Heart $J$ 1980; 44:577-83.

12 Soto B, Pacifico AD, Souza AS Jr, Bargeron JM Jr, Ermocilla R, Tonkin IL. Identification of thoracic isomerism from the plain chest radiograph. $A J R$ 1978;131:995-1002.

13 Rigby ML, Anderson RH, Gibson D, Jones ODH, Joseph MC, Shinebourne EA. Two dimensional echocardiographic categorisation of the univentricular heart. Ventricular morphology, type, and mode of atrioventricular connection. Br Heart J 1981; 46:603-12.

14 Piccoli GP, Wilkinson JL, Macartney FJ, Gerlis LM, Anderson RH. Morphology and classification of complete atrioventricular defects. Br Heart J 1979; 42:633-9.

15 Rastelli GC, Kirklin JW, Titus JL. Anatomic observations on complete form of persistent atrioventricular canal with special reference to atrioventricular valves. Mayo Clin Proc 1966;41:296-308.

16 Keeton BR, Macartney FJ, Hunter S, et al. Univentricular heart of right ventricular type with double or common inlet. Circulation 1979;59:403-11.

17 Bharati $S$, Lev $M$. The spectrum of common atrioventricular orifice (canal). Am Heart J 1973;86: 553-61.

18 Bharati S, McAllister HA, Lev M. Straddling and displaced atrioventricular orifices and valves. Circulation 1979;60:673-84.

19 Freedom RM, Bini M, Rowe RD. Endocardial cushion defect and significant hypoplasia of the left ventricle: a distinct clinical and pathological entity. Eur $J$ Cardiol 1978;7:263-81. 